\title{
Utilization of Endophytes Fungi from Jatropha Leaves (Jatropha curcas L.) Against Fusarium oxysporum Causing Tuber Rot Disease Onion (Allium cepa var. Ascalonicum (L.) Backer)
}

\author{
Akhmad Rizali* (D) and Rabiatul Wahdah \\ Department of Agroechotechnology, Agriculture Faculty, Lambung Mangkurat University, Indonesia.
}

\begin{abstract}
Tuber rot is one of the important diseases in onion caused by Fusarium oxysporum. Endophytes are biological agents that are currently widely used in controlling plant diseases. Excessive use of pesticides and continuously has shown negative impacts such as resurgence, resistance to pests and pathogens, and the death of natural enemies. Currently, pests and pathogens control effort are directed at the utilization of natural enemies or better known as biological control. Endophyte is a microorganism that grows in plant tissues without causing symptoms. Endophytes allegedly capable of producing a variety of phytochemical compounds generated by their host. The leaves of Jatropha (Jatropha curcas L.) is one part of the plant that contains secondary metabolites.Phytochemical tests on the Jatropha show that Jatropha contains alkaloids, flavonoids, and saponins that are an antimicrobial potential of plant-pathogen control agents. This study aimed to determine the effect of some Endophytes isolates and their impact on the growth of $F$. oxysporum in vitro in onion. Exploration (endophyte isolation from Jatropha healthy leaves) and observation (antagonist test of Endophytes of the Jatropha leaves) method used in this study was a Completely Randomized Design (CRD) with a single factor (10 treatment) repeated three times. There were 14 endophytes isolated from Jatropha leaves with a growth ratio of $4.5 \mathrm{~cm} / 2$ days. The best treatment to inhibit the growth of $F$. oxysporum in vitro is Jc5, Jc8, Jc10.

Keywords: Biological Agents, Inhibition, Pathogenicity, antagonistic
\end{abstract}

*Correspondence: arizali25@yahoo.com
(Received: January 23, 2020; accepted: September 17, 2020)
Citation: Rizali A, Wahdah R. Utilization of Endophytes Fungi from Jatropha Leaves (Jatropha curcas L.) Against Fusarium
oxysporum Causing Tuber Rot Disease Onion (Allium cepa var. Ascalonicum (L.) Backer). J Pure Appl Microbiol. 2020;14(4):
2655-2660. doi: 10.22207/JPAM.14.4.42
() The Author(s) 2020. Open Access. This article is distributed under the terms of the Creative Commons Attribution 4.0 International License which
permits unrestricted use, sharing, distribution, and reproduction in any medium, provided you give appropriate credit to the original author(s) and
the source, provide a link to the Creative Commons license, and indicate if changes were made. 


\section{INTRODUCTION}

Red onion is one of the featured vegetable crops that have long been intensively cultivated by farmers. Shallots belong to a group that serves as a spice seasoning and traditional medicine. National shallot production is sufficient to supply the domestic consumption, but its production fluctuates under abnormal climatic conditions (Kelvin, 2014). One of the important diseases in shallot is a tuber rot caused by Fusarium oxysporum.The disease causes direct damage to the tubers and reduces tuber yield by 50\% (Zuleika, 2014). Korlina et al. (2000) suggested that damage caused by tuber rot can reach $75 \%$ at 42 days after planting (DAP) and will increase if not controlled. Pathogen control is generally conducted by utilizing pesticides. Excessive use of pesticides has shown negative impacts such as resurgence, resistance to pests and pathogens, and the death of natural enemies.Currently, pests and pathogens control effort directed at the utilization of natural enemies of pets and pathogens, or better known as biological control. One of the biological control efforts is using endophyte.

Endophytes microbes are microbes that live in healthy plant tissues such as leaves, flowers, branches, or roots without causing symptoms of the disease. Endophyte performs beneficial symbiosis with the host plant, where they get the nutrients from plant metabolism, and produce secondary metabolites that help the host against pathogen attack. (Taechowishan et al., 2003). Endophytes phytochemistry can produce various compounds that are also produced by the host plant. It is considered related to the presence of genetic recombination between endophyte and its host during its evolution.

Jatropha (Jatropha curcas L.) has been widely used as a traditional medicine in the community, especially the leaves. Jatropha also has high potential for the development of medicinal products for agriculture and chemical industries. Jatropha extracts showed antimicrobial and antioxidant activity (Windarwati, 2011). Phytochemical test of its roots, leaves, seeds, and bark indicates that Jatropha contains flavonoids, saponins, alkaloids, terpenoids which have antimicrobial and bioactive potential to control plant pathogens (Chain et al., 2013).

\section{MATERIALS AND METHODS}

Materials used in this study were $F$. oxysporum isolates, Jatropha healthy leaves, PDA, sterile distilled water, and $70 \%$ alcohol. A tool used in this study were petri dish, pipette, needle ose, aluminum foil, cotton, cling wrap, Enkas, autoclave, bunsen burner, microscopes, glass beaker, tweezers, scissors, analytical balance, calipers, and a scalpel blade,

\section{Sterilization Equipment}

All the glassware used was washed with running water until clean, then dried. After drying, the apparatus which has a mouth surface was plugged with cotton. Then, all the tools were wrapped in newsprint and sterilized by autoclaving for ten minutes at $121^{\circ} \mathrm{C}$.

\section{PDA Media Preperation}

About $200 \mathrm{~g}$ of potatoes were washed thoroughly, then cut into small pieces and boiled in $1000 \mathrm{ml}$ of distilled water until tender. $20 \mathrm{~g}$ dextrose and $20 \mathrm{~g}$ agar should be added and stir until blended. After boiling, the PDA then poured into the Erlenmeyer, and the mouth was plugged with cotton and wrapped with aluminum foil. Furthermore, the media was sterilized using autoclave at $2 \mathrm{~atm}, 121^{\circ} \mathrm{C}$ for 30 minutes.

Endophytes Isolation of Jatropha leaves, Purification, and the Distance Measurement Growth

Jatropha healthy leaves were cleaned with alcohol and distilled water and then dried on filter paper. The leaves were cut into small pieces of $0.5 \times 0.5 \mathrm{~cm}$ and placed into a dish containing PDA medium. The edge of the petri dish was sterilized using a Bunsen burner. Then it was covered with cling wrap and incubated for 7 days. On the 7th day, the isolate from each leaf was purified. Cup containing pure isolates from each Endophytes growth were measured on days 3,5 , and 7 after inoculation (DAI).

\section{Inhibitory Power Test}

The inhibition test (antagonism test) was conducted using a double culture (dual culture). On the 7th day after purification, Endophytes pathogens that grow to $9 \mathrm{~cm}$ diameter will be divided into 3 parts $(3 \mathrm{~cm}$ each) then incubated for 7 days at room temperature. 


\section{RESULTS AND DISCUSSION \\ Endophytes Isolation and Purification of Jatropha leaf (Jatropha curcas L.)}

A total of 20 pure Endophytes isolates were obtained from Jatropha leaf isolation (J. curcas L.) but out of 20 endophyte pure, they were only 14 isolates can grow well namely Jc1, Jc2, Jc3, Jc4, Jc5, Jc6, Jc7, Jc8, Jc9, Jc10, Jc11, Jc12, Jc13, and Jc14. Microscopic observation showed that all the endophytes have antagonist potency as an agent because of its higher growth than the F. oxysporum. Shehata et al. (2008) state that one of the characteristics of microbial antagonists is characterized by faster growth compared to the pathogen.

Mycellium growth of Jatropha leaf Endophytes isolates (Jatropha curcas L.) and Fusarium oxysporum

Based on Fig. 1, on the 3rd to 5th day, the mycelia growth of each isolate increase sharply. It is estimated to occur because fungal isolates were in the exponential/logarithmic phase. Whereas, isolates showed a low growth on 5 to 7-day. This may occur because endophyte enters the stationary phase so that the growth rate decreases. In the exponential phase, the isolates will grow fast and constant. In this phase, the fungus becomes very sensitive to the environment and require higher energy to consume nutrients in the media. At the end of the exponential phase, the fungus will produce metabolic waste that might inhibit growth. While in stationary phase, the number of cells grow and die will be equal.

Based on Fig. 2, the highest mycelium growth was shown by Jc10 isolate of $8.1 \mathrm{~cm} / 2$ days. The lowest mycelium growth was shown by Jc4 and Jc14 isolates, which was $4.5 \mathrm{~cm} / 2$ days. Power Test Method with Dual Inhibition Culture Analysis of variance at $5 \%$ level showed that the inhibitory variable of Endophytes isolates against $F$. oxysporum was insignificant. Inhibition test test showed that some Endophytes

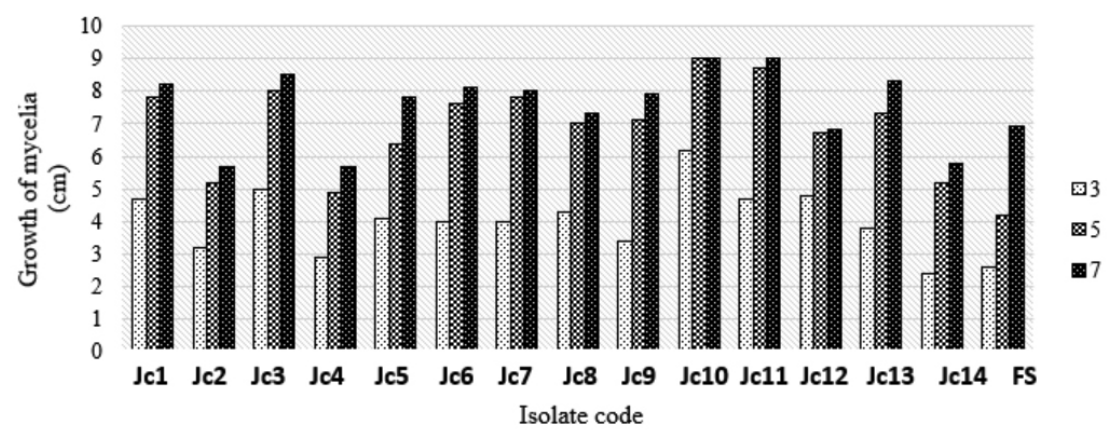

Fig. 1. Mycelia growth of Jatropha leaf Endophytes isolates (J. curcas L.) and F. oxysporum on 3, 5, and 7 days after inoculation (DAI).

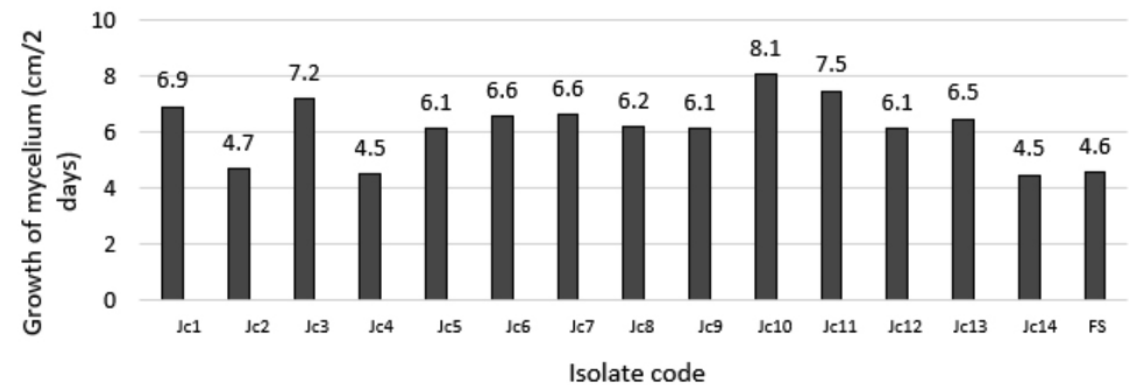

Fig. 2. Mycelium growth of Jatropha leaves Endophytes isolates (J. curcas L.) and F. oxysporum. 
isolates grew more active than $F$. oxysporum. This was indicated by the average value of percent inhibition against F. oxysporum, which was more than $40 \%$. The inhibitory ability of fungal antagonist is caused by differences in the production of secondary metabolites, which are determined by the type, antagonists fungal strains, and types of pathogens. Secondary metabolites cause inhibition of pathogenic Endophytes growth. Also, it is influenced by the type and concentration of the antibiotic compound, the presence of other fungi, the balance rate of

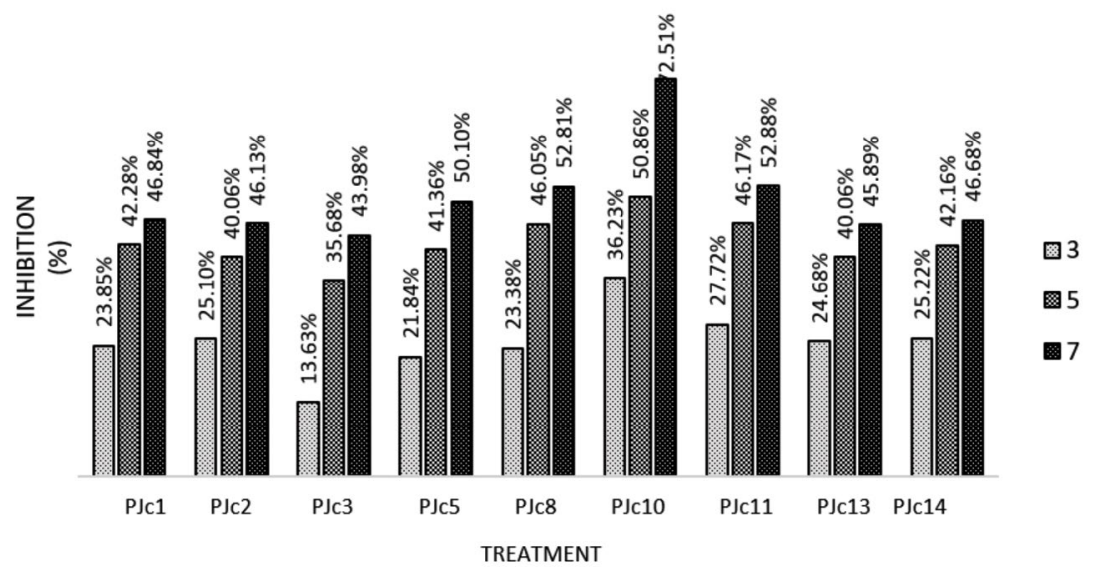

Fig. 3. Power Inhibition Assay results Endophytes of Jatropha leave (J. curcas L.) with the pathogen F. oxysporum on 3,5 , and 7 days after incubation (DAI).

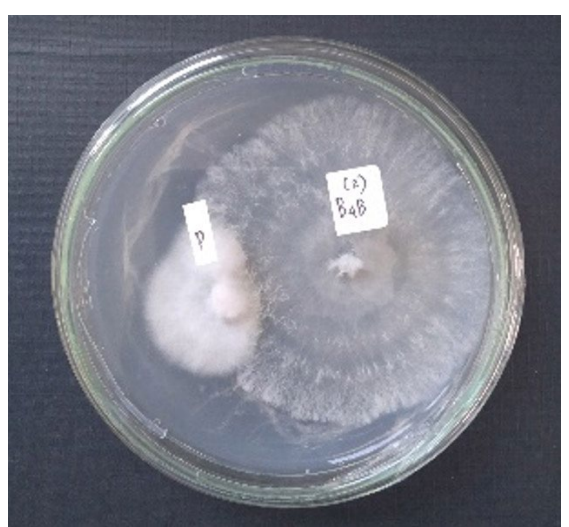

Fig. 4. Dual culture in PJc10

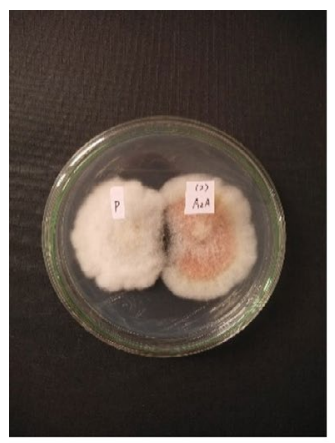

PJc5

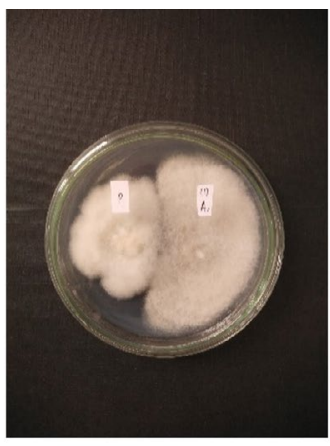

PJc8 biosynthesis, and biotransformation (Vinale et al., 2009). The highest percentage yield resistor was PJc 10 treatment with inhibition percentage of $73.51 \%$, while the lowest was Pjc3 of $43.98 \%$. The dominance of space that occurs in PJc10 treatment associated with endophyte Jc4 current growth rate of purification (Fig. 2). The ability to inhibit pathogens in PJc10 treatment is estimated due to its ability to dominate the nutrient, so it can grow fast and inhibit the growth of pathogenic F. oxysporum. The space factor becomes one of the important factors that affect the endophytes performance. The endophytes can grow faster and

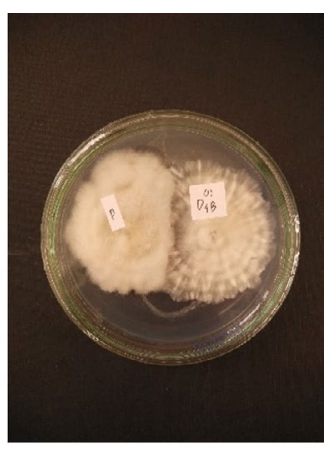

PJc11

Fig. 5. Dual culture in PJc5, PJc8, and PJc11 treatment 
suppress the growth of pathogenic antagonistic agents so that they cannot develop. While on the PJC3 treatment, the inhibition percentage is relatively low compared to other treatments. It is in contrast with the growth rate when pure Jc3 isolate is cultured (Fig. 2). The low percentage of inhibition on PJC3 treatment allegedly because when cultured with dual culture method $F$. oxysporum produces toxins that inhibit the growth of Jc3 Endophytes.

Several treatments show a vary percentages, and others have inhibitory above $50 \%$, such as PJc5, PJc8, PJc11, and PJc10 (Fig. 3). Fig. 3 also shows the highest inhibitory ability is in the PJc10 treatment, with a value of $72.51 \%$.

The results show that PJc10 treatment was able to dominate space faster than other treatments. PJc5, PJc8, and PJc11 treatment show a lower ability in dominating space compare to PJc10 treatment. However, the three endophytes show the ability to inhibit the growth of pathogens, characterized by color changes in the contact area.

Antagonistic microorganisms can use one or more mechanisms to suppress the pathogen, and its performance can be different for other pathogens. The interaction between pathogen and endophyte based on three criteria: competition, antibiosis, and parasitism. Competition mechanism has shown in PJc10 treatment. It shows that endophyte colonies grow over the pathogenic colonies and grow faster in the Petri dish.

In PJc5, PJc8, and PJc11 treatment, discoloration occurred at the contact point between pathogen and endophyte. It may occur because the PJc5, PJc8, and PJc11 endophyte have the antagonism ability against pathogens by attaching hyphae to pathogens then secrete enzymes that degrade the cell. The activity of these enzymes causes damage and discoloration in cell walls of pathogenic hyphae. PJc8 and PJc13 treatment are supposed to have parasitism ability against pathogens. This demonstrated by the growth of Endophytes mycelia above pathogens. Fungal hyphae that grow on the surface of pathogens will wrap the pathogen hyphae so that pathogen cells will undergo lysis.

\section{CONCLUSION}

Antagonistic microorganisms can use one or more mechanisms to inhibit the growth of starch and their performance can be different against other types of pathogens. The interaction mechanism that occurs between pathogens and endophytes is based on three criteria, namely competition, antibiosis and parasitism. The competition mechanism can be shown in PJc10 treatment because endophytic colonies grow to cover the coloni of pathogens and endophyte growth fills the petri dishes faster. Organisms with fast growth have the ability to produce antibiotics and tolerant of antibiotics produced by other organisms.

Based on the results obtained, it is concluded that Endophytes isolates derived from the leaves of Jatropha (J. curcas L.) can inhibit growth of the pathogen $F$. oxysporum on onion in vitro, and the best treatment is PJc5, PJc8, PJc10, and PJc11 with the percentage of inhibition ranged from $50.1 \%-72.52 \%$.

\section{ACKNOWLEDGMENTS}

The authors would like to thank Ir. Jumar, M.P as head department of Agroechotechnology, University of Lambung Mangkurat, for providing Fusarium oxysporum and Trichoderma spp.

\section{CONFLICT OF INTEREST}

The authors declare that there is no conflict of interest.

\section{AUTHORS' CONTRIBUTION}

All authors listed have made a substantial, direct and intellectual contribution to the work, and approved it for publication.

\section{FUNDING}

None.

\section{ETHICS STATEMENT}

Not applicable.

\section{DATA AVAILABLILTY}

All datasets generated or analyzed during this study are included in the manuscript.

\section{REFERENCES}

1. Ajith PS, Lakshmidevi N. Effect of Volatile and Novolatile Compounds from Trichoderma spp. Against Colletotrichum capsici Incitant of Anthracnose on Bell Peppers. Nature and Science. 2010;8(9):265-269.

2. Athman S, Dubois T, Viljoen A, et al. In Vitro Antagonism 
of Endophytic Fusarium oxysporum Isolate Against The Burrowing Nematode Radopholus similis. Namatology. 2006;8:627-636. doi: 10.1163/156854106778613976

3. Carrol GC. Fungal Endophytes in stem and leaves. From Latent Pathogens to Mutualistic Symbiont. Journal of Ecology. 1988;69(1):2-9. doi: 10.2307/1943154

4. Chen XH, Koumoutsi A, Scholz R, Eisenrech A, Schneider K, Schneider I. Comparative Analysis of The Complete Genom Sequence of The Plant Growth Promoting Bacillus amyloliquefaciens FZB 42. Nat. Biotechnol. 2007;25:1007-1014. doi: 10.1038/nbt1325

5. Chodary DK, Prakash A, Johri BN. Induced Systemic Resistance (ISR) in Plants: Mechanism of Action. Indian J Microbiol. 2007;47:289-297. doi: 10.1007/s12088007-0054-2

6. Choudary DK, Johri BN, Prakash A. Volatiles as Priming Agent That Initiate Plant Growth and Defence Responses. Curr Sci. 2008;94:595-604.

7. Korlina E, Rosmahani L, Baswarsiati F, Kasijadi ER. Assessment of Farm Teknlogi Assembled Onions Planting Off Season. In: Smith et al. Proceedings of the Research Seminar. BPTP assessment Karangploso. Poor. 2000:160-171.

8. Rante HB Taebe, Diamond S. Isolation of Endophytic Fungi Producing Antimicrobial Compounds from Leaves Katokkon Chilli (Capsicum annum L. var. Chinensis) and
Profile TLC Bioautografi. MFF. 2013;17(2): 39-46.

9. Fawzy SS, Borollosy AM. Induction and Growth Yellow Mosaic Potyvirus enchancement of Squash Plants Using Some Plant Growth Promoting Rhizobacteria. Aust J Basic Appl Sci. 2008;2: 174-182.

10. Vinale F, Ghisalberti EL, Sivasithamparam K. Factors Affecting The Production of Trichoderma harzianum Secondary Metabolites During The Interaction with Different Plant Pathogens. Lett Appl Miccrobiol. 2009;48:705-711. doi: 10.1111/j.1472765X.2009.02599.x

11. Walker JC. Plant Pahology. Mc Graw-Hill Book Co. Inc. New York. 1975.

12. Windarwati S. Utilization of Plant Extracts Active Fraction (Jatropha curcas L.) As Antimicrobials and Antioxidants Substances In Cosmetic preparations. Thesis. Bogor Agricultural Institute. Bogor. 2011.

13. Zhang Z, Li Q, Li Z, Staswick PE, Wang M, Zhu Y. Dual Regulation Role of GH3.5 in Salicylic Acid and Auxin Signaling During Arabidopsis-Pseudomonas syringae interaction. Plant Physiol. 2007;145:450-464. doi: 10.1104/pp.107.106021

14. Zuleika. Endophytic Fungus of 2014. Utilization in Control of Tuber rot (Fusarium oxysporum) in Onion (Allium cepa var. Aggregatum). Thesis. Faculty of Agriculture, IPB. Bogor. 